\title{
Ventricular Size, Cognitive Function and Depression in Patients with Multiple Sclerosis
}

\author{
Campbell M. Clark, Gerald James, David Li, Joel Oger, \\ Donald Paty and Harry Klonoff
}

\begin{abstract}
The purpose of this study was to explore further the hypothesis that changes in cognitive function may occur in the mild stages of multiple sclerosis (MS) by determining whether ventricular enlargement was related to cognitive function. Ten measures of ventricular size were made in a sample of 123 MS patients with mild disability and 60 well-matched healthy controls. In addition, sixteen tests of cognitive function and the Beck Depression Inventory were administered. For the MS group, there were significant correlations between the ventricular measures and cognitive performance but not for the normal controls. Scores on the Beck Depression Inventory were not correlated with either cognitive performance or ventricular enlargement. These findings suggest that for the MS group cognitive impairment was related to the disease process but not to the level of depression.
\end{abstract}

RÉSUMÉ: Taille des ventricules, fonction cognitive et dépression chez les patients atteints de sclérose en plaques. Le but de cette étude était d'explorer davantage l'hypothèse selon laquelle des changements dans la fonction cognitive peuvent survenir aux stades peu sévères de la sclérose en plaques (SEP) en déterminant si l'augmentation de la taille des ventricules était reliée à la fonction cognitive. Dix mesures de la taille ventriculaire ont été faites chez un échantillon de 123 patients atteints de SEP, qui avaient une invalidité peu sévère, et 60 contrôles sains bien appariés. De plus, seize épreuves de fonction cognitive et le questionnaire de Beck ont été administrés. Chez le groupe de patients atteints de SEP, il y avait des corrélations significatives entre les mesures ventriculaires et la performance cognitive qui n'étaient pas présentes chez les contrôles normaux. Les scores au questionnaire de Beck n'étaient pas correlérs à la performance cognitive ou à l'augmentation de la taille des ventricules. Ces résultats suggèrent que, chez le groupe de patients atteinte de SEP, l'atteints cognitive était reliée au processus morbide et non au niveau de dépression.

Can. J. Neurol. Sci. 1992; 19: 352-356

Although cognitive impairment including dementia is wellrecognized in multiple sclerosis (MS) when patients are disabled, there is an increasing body of evidence suggesting that cognitive impairment may also be present in the early or mild stages of this disease. ${ }^{1-5}$ Studies have compared a sample of normal controls with MS patients in the early stages of disease and reported differences on tests of memory, learning or attention. ${ }^{1-9}$ In such studies the establishment of a direct causal relationship is confounded by other variables which may be secondary effects of MS. For example, in response to the diagnosis of MS, individuals may become depressed ${ }^{10-12}$ and poorer performance in tests of memory, learning and attention have also been associated with depression. ${ }^{13}$ These mood problems may become exacerbated during the actual testing. In contrast, normal subjects may view the testing as a challenge to their intellect and be highly motivated to perform well. Therefore, a more convincing argument that these cognitive changes are truly direct effects of the disease process is to show there is a relationship between measures of cognition and pathological changes within the brain. Conversely, one should also show that for these patients relationships do not exist between the level of depression, cognitive function and pathological changes within the brain. To further support this argument, the found relationships between changes within the brain and cognitive performance should not be present within a normal sample. Two measures of brain pathology which have been employed in the past are ventricular enlargement and lesion load as determined by computerized tomography (CT) or magnetic resonance imaging (MRI). The published studies examining the relationship between these measures of brain pathology and cognitive function have confined their sampling to MS patients. ${ }^{3.14-15}$ There are, however, other studies suggesting that with normal aging ventricles may enlarge or periventricular lesions may appear. ${ }^{16-19}$ Hence, if there is no control group in a study, one cannot be assured that

From the Department of Psychiatry, (C.M.C.); Department of Radiology, (D.L.); Division of Neurology, Department of Medicine, (J.O., D.P.); Professor Emeritus, Department of Psychiatry (H.K.)

Received September 24, 1991. Accepted in final form January 27, 1992

Reprint requests to: Dr. Campbell Clark, Department of Psychiatry, The University of British Columbia, 2255 Wesbrook Mall, Vancouver, British Columbia, Canada V6T 2AI 
the found relationships are a function of the disease process and not normal aging as memory functions also appear to decline with normal aging. ${ }^{20,21}$

The purpose of the current study was to examine the relationship between measures of ventricular size, cognitive ability and depression in a sample of MS patients with mild clinical symptoms and a well-matched sample of healthy controls. Rather than use a global measure of ventricular size such as the ventricle brain ratio, ten different aspects of the ventricular system were measured. The reason for this approach was that in MS patients there may be different effects on the ventricular system dependent upon the site(s) of the lesion. The effects of lesions upon cognitive functions may also be site-related and hence, may have different effects on cognitive processes among MS patients. Therefore, the patients were assessed using a comprehensive battery (16 tests) consisting, in the main, of tests previously shown to be affected by MS. In addition, the Beck Depression Inventory was administered to all subjects.

\section{MethodS}

\section{Subjects}

The subjects were recruited from the UBC:MS Clinic and had to meet the following criteria: 1) diagnosis of clinically definite MS with a relapsing/remitting course; ${ }^{22} 2$ ) in remission at the time of assessment; 3) no other medical diseases; 4) no history of psychiatric illness prior to diagnosis of MS; 5) no history of drug or alcohol abuse; 6 ) medication-free at the time of testing; 7) aged less than 40 at the time of diagnosis $(\bar{X}=30.7$ years) and aged less than 50 at time of assessment (age at time of diagnosis $=30.7$, duration of disease $=5.0$ years, number of relapses per year $=0.99$ ); and 8 ) a score of less than 6.0 on the Kurzke Extended disability scale $(\bar{X}=2.1, S D=1.3$, range 0 5.0, frequency of EDSS scores $0-1.5, \mathrm{n}=59 ; 2.0-3.5, \mathrm{n}=56$; $>3.5, \mathrm{n}=23) .{ }^{23}$ Wherever possible, each subject was asked to recruit a same sex unrelated control with a similar socio-economic background. The resulting samples consisted of $123 \mathrm{MS}$ patients ( 33 males and 90 females) and 60 controls (17 males and 43 females). As expected, these two groups did not differ on age $(\bar{X}=36.2,35.7$ years for the MS and control groups, $t=$ $0.41)$ or education $(\bar{X}=13.6,13.4$ years for the respective groups, $t=0.61$ ). These procedures were approved by the University of British Columbia Clinical Screening Committee, and informed consent was obtained from all subjects.

\section{MRI Scans and Ventricular Measures}

All subjects were scanned using a Picker International Cyrogenic MR 2000 scanner operating at 0.15 Tesla. Images were obtained using a simultaneous multiple 12-slice spin echo sequence with a repetition time of $2,000 \mathrm{msec}$ and an echo time of $60 \mathrm{msec}$ in the transverse plans. From this 12 slice array, slices were selected such that the size of the ventricular measures of interest were maximized. These measures were the areas of the right and left lateral ventricles, the right and left frontal horns, the right and left occipital horns and the third ventricle as well as the width of the third ventricle, the bifrontal span and the bicaudate span (10 measures total). These slices were digitized and calibrated using the Microcomputer Imaging Device (MCID). ${ }^{24}$ Areas of interest were outlined by hand using a track-ball and the area was computed converting the pixel count to square centimeters. Width measures were done similarly. All outlining was done by the same individual who was blind in terms of cognitive performance and level of depression. Although initially blind to diagnosis, the lesions in the MS patients were not disguised.

\section{Psychological Tests}

The cognitive tests were administered on the same day as the scan. Order of presentation was randomized and these tests were part of a larger battery which also had measures of sensory and motor functions. The tests were: 1) the Wechsler Adult Intelligence Scale - the best validated test of general intellectual functions which yields estimates of verbal abilities (VIQ), performance abilities (PIQ) and a composite overall estimate of intellectual functions (FIQ); 2) a modified version of the Halstead-Reitan Organicity Battery including shortened forms of the Halstead Category Test (CAT); the Tactual Performance Test (dominant speed, TPTd; non-dominant speed, TPT nd; bilateral speed, TPTb; memory, MEM; and spatial location, LOC), and the Speech Perception Test (Speech); and 3) a collection of tests on which MS patients have been shown previously to perform poorer than normal subjects, namely, the Benton Visual Retention Test (BVRT), the Word Fluency Test (W.F.), Trails $A$ and $B$ and paired associate learning (P.A.). With the exception of VIQ, the tests selected have been shown to be sensitive to cognitive changes in MS samples, typically more clinically disabled than this one. In addition, each subject completed a Beck Depression Inventory. A description of the neuropsychological tests is presented in an Appendix.

\section{Analyses}

The data were analyzed from three perspectives. First, the ventricular measures were compared between the two samples using multivariate analysis of variance procedures and Bonferonni corrected $t$-tests for the individual comparisons. The purpose of this analysis was to ensure that the MS sample did exhibit enlargement of the ventricles in comparison to normals. Any measure where a significant difference in either means or variance was not found between the controls and the MS patients was excluded from further analysis. Second, the cognitive measures were compared between the two groups using identical procedures to those outlined above while the depression scores were compared using a t-test. The purposes of this analysis were to determine, one, whether cognitive impairment was present in the MS group, and two, whether the MS group was more depressed than the controls. Again, any variable where a significant difference was not found was excluded from subsequent analysis. The final and critical analyses were: 1) to determine whether there was significant relationship between the measures of ventricular enlargement and the cognitive tests or the Beck score; and 2) to determine if these relationships are consistent with or different from those found in normal subjects. Therefore, correlation matrices of ventricular measures with cognitive tests and the Beck were calculated. These matrices were compared in terms of the number of significant correlations. To support the hypothesis that cognitive impairment in MS patients is related to the integrity of the brain, one must show that: 1) there is relationship among these measures in MS patients and; 2) these relationships are not present in normal subjects; and 3) the level of depression is not related to ventricular 
change or performance on the cognitive tests. In addition, for the MS group, the EDSS was correlated with the measures of ventricular enlargement.

\section{REsults}

\section{Ventricular Measures}

The comparison of the MS patients and control subjects on the 10 measures of ventricular enlargement yielded a significant multivariate $\mathrm{F}$-value $(\mathrm{FI}, 10,172=4.00, \mathrm{p} \leq 0.001)$ with eight of the ten Bonferonni contrasts being significant. Therefore, one may conclude that ventricular enlargement was present in the MS group. These data are presented in Table 1. The only two measures where the MS group and the controls did not differ in terms of means were the width of the third ventricle and bifrontal span. However, for the third ventricle width, the variance was significantly greater in the MS group $\left(\mathrm{F}_{1.60}=19.0, \mathrm{p} \leq\right.$ 0.001 ) thus suggesting for a subsample of the MS group, the third ventricle width was greater. Therefore, only bifrontal span was excluded from the correlational analyses.

\section{Cognitive Tests}

For the 16 cognitive tests, the comparison of the MS group and the normal controls also yielded a significant multivariate F-value $(\mathrm{F} 1,16,166=2.52, \mathrm{p} \leq 0.002)$ with 12 of the 16 Bonferonni contrasts being significant. These data are presented in Table 2. Here, one may tentatively conclude that the MS and control subjects differed in terms of cognitive ability. The four tests where no differences were found were VIQ, CAT, LOC and Speech. As no significant differences were found for these four variables, they were excluded from the correlational analysis.

With respect to the relationship between ventricular enlargement and cognitive function, for the MS group 29 of the 108 possible correlations were significant ( $\mathrm{p} \leq 0.05$, two-tailed) whereas for the normal group none of the correlations were significant; thus, suggesting that relationship is a function of ventricular enlargement resulting from MS and not a normal phenomenon. Given the number of possible correlations (i.e., 108), a chi-squared analysis was done to ensure that the number of found significant correlations in the MS group (i.e., 29) significantly exceed chance expectancy (i.e., 6 significant correlations). The chi-squared value was significant $\left(X^{2}=16.5, \mathrm{df}=1\right.$, $p \leq 0.0001)$. Therefore, one may conclude that ventricular enlargement is significantly related to cognitive impairment in

Table 1. Comparison of Ventricular Measure

\begin{tabular}{|c|c|c|c|c|c|c|}
\hline \multirow{2}{*}{\multicolumn{2}{|c|}{ Measure/Group }} & \multicolumn{2}{|c|}{$\operatorname{MS}(n=123)$} & \multicolumn{2}{|c|}{ Normals $(n=60)$} & \multirow[t]{2}{*}{ t-value } \\
\hline & & $\frac{x}{x}$ & S.D. & & S.D. & \\
\hline Paired Lateral & $\begin{array}{l}\text { Left } \\
\text { Right }\end{array}$ & $\begin{array}{l}7.78 \\
7.52\end{array}$ & $\begin{array}{l}2.35 \\
1.97\end{array}$ & $\begin{array}{l}6.65 \\
6.53\end{array}$ & $\begin{array}{l}1.53 \\
1.34\end{array}$ & $\begin{array}{l}3.63^{*} \\
3.52^{*}\end{array}$ \\
\hline Frontal Horn & $\begin{array}{l}\text { Left } \\
\text { Right }\end{array}$ & $\begin{array}{l}1.73 \\
1.64\end{array}$ & $\begin{array}{l}0.67 \\
0.64\end{array}$ & $\begin{array}{l}1.43 \\
1.36\end{array}$ & $\begin{array}{l}0.38 \\
0.34\end{array}$ & $\begin{array}{l}3.25^{*} \\
3.14^{*}\end{array}$ \\
\hline Occipital Horn & $\begin{array}{l}\text { Left } \\
\text { Right }\end{array}$ & $\begin{array}{l}2.73 \\
2.53\end{array}$ & $\begin{array}{l}1.02 \\
0.81\end{array}$ & & $\begin{array}{l}0.49 \\
0.43\end{array}$ & $\begin{array}{l}5.48^{*} \\
5.39^{*}\end{array}$ \\
\hline $\begin{array}{r}\text { Third: Area } \\
\text { Width }\end{array}$ & & $\begin{array}{l}1.24 \\
0.58\end{array}$ & $\begin{array}{l}0.61 \\
0.61\end{array}$ & $\begin{array}{l}0.95 \\
0.45\end{array}$ & $\begin{array}{l}0.36 \\
0.14\end{array}$ & $\begin{array}{l}3.37^{*} \\
1.69\end{array}$ \\
\hline $\begin{array}{l}\text { Bifrontal Span } \\
\text { Bicaudate Span }\end{array}$ & & $\begin{array}{l}3.39 \\
1.14\end{array}$ & $\begin{array}{l}0.43 \\
0.34\end{array}$ & $\begin{array}{l}3.39 \\
0.99\end{array}$ & $\begin{array}{l}0.29 \\
0.21\end{array}$ & $\begin{array}{l}0.05 \\
3.17^{*}\end{array}$ \\
\hline
\end{tabular}

"Significant difference $(\mathrm{p} \leq 0.05)$ between groups using Bonferroni correction.
Table 2. Comparisons of Cognitive Tests

\begin{tabular}{lrrrrr}
\hline \hline $\begin{array}{l}\text { Cognitive } \\
\text { Test/Group }\end{array}$ & \multicolumn{2}{c}{ MS $(\mathbf{n}=\mathbf{1 2 3})$} & \multicolumn{2}{c}{ Normals $(\mathbf{n}=\mathbf{6 0})$} & t-value \\
$\mathbf{X}$ & \multicolumn{1}{c}{ S.D. } & \multicolumn{1}{c}{$\mathbf{X}$} & \multicolumn{1}{c}{ S.D. } & \\
\hline FIQ & 103.4 & 11.0 & 108.7 & 11.0 & $2.99^{*}$ \\
VIQ & 105.5 & 10.9 & 108.0 & 11.9 & 1.40 \\
PIQ & 100.1 & 12.9 & 108.1 & 10.8 & $3.77^{*}$ \\
BVRT (errors) & 4.0 & 2.7 & 3.1 & 2.2 & $2.40^{*}$ \\
WF & 36.3 & 10.7 & 42.7 & 10.7 & $3.70^{*}$ \\
CAT (errors) & 22.7 & 14.0 & 20.4 & 12.5 & 1.07 \\
TPTd (time) & 2.5 & 1.1 & 1.9 & 0.86 & $3.14^{*}$ \\
nd & 1.9 & 1.3 & 1.5 & 0.8 & $2.39^{*}$ \\
both & 1.1 & 0.9 & 0.8 & 0.5 & $2.78^{*}$ \\
Mem & 4.5 & 1.3 & 5.0 & 1.0 & $2.52^{*}$ \\
Loc & 3.7 & 1.7 & 4.1 & 1.5 & 1.32 \\
Speech (errors) & 4.3 & 4.1 & 3.3 & 2.3 & 1.74 \\
Trails A & 29.7 & 12.2 & 25.7 & 8.0 & $2.24^{*}$ \\
& 64.1 & 26.1 & 55.5 & 17.3 & $2.27^{*}$ \\
PA B & 44.2 & 7.0 & 47.3 & 5.5 & $2.96^{*}$ \\
Mem Ob. & 12.1 & 1.7 & 13.0 & 1.4 & $3.33^{*}$ \\
\hline
\end{tabular}

*Significant difference ( $\mathrm{p} \leq 0.05)$ between groups using Bonferroni correction

Legend: FIQ, VIQ, PIQ: Full Scale, Verbal and Performance Intelligence Quotients respectively; BVRT: Benton Visual Retention Test; WF: Word Fluency; CAT: Halstead Category; TPTd, nd, both: Tactual Performance Test for dominant, non-dominant and both hands; Mem: memory; Loc: location; Speech: speech perception test; PA: paired associated learning; Mem Ob.: memory for objects.

MS patients. It should be noted that when variables where no significant differences were included in these analyses, the chisquared tests were still significant $\left(\mathrm{X}^{2}=6.5, \mathrm{df}=1, \mathrm{p} \leq 0.05\right)$. However, for brevity, these data were excluded. The correlations among these variables for the MS patients are given in Table 3. The areas with the highest number of correlations were the left occipital horn (6/12) followed by left paired lateral ventricle $(5 / 12)$. Although there was a trend for left-side areas to be more correlated with test scores than right $(12 \mathrm{v} / \mathrm{s} 6)$, this difference was not significant $\left(\mathrm{X}^{2}=1.85\right.$, df $\left.=1, \mathrm{p} \leq 0.18\right)$. Finally, it should be noted that although these correlations were significant, their magnitude was not large; the highest value being 0.33 . For the cognitive measures, Trail-Making Parts A \& B had the largest number of significant correlations (6/9). In contrast, for the EDSS, a measure of clinical disability, only one correlation was significant.

\section{Beck Depression Inventory}

As expected, the MS patients had significantly higher levels of depression than the control group $(\mathrm{Xms}=7.04$, $\mathrm{Xcont}=3.62$, $t=4.90, d f=143.10, p \leq 0.001)$. In addition, the variance of the scores for the MS group was significantly greater $(\mathrm{SDms}=5.2$, SDcont $=3.9$, Hartley Fmax $=1.72, p \leq 0.03$ ). However, for the MS group, none of the correlations with the ventricular measures were significant. In fact, no correlation exceeded 0.09. When the Beck scores were correlated with performance on the cognitive tests, no significant correlations were found for the MS group. This finding suggests that for this sample, the tests of cognitive performance and level of depression were independent.

\section{Discussion}

The cardinal findings in the current study are that for mild cases of MS in remission, there is evidence of cognitive 
Table 3. Correlations of Ventricular and Cognitive Measures in MS patients $(n=123)$

\begin{tabular}{|c|c|c|c|c|c|c|c|c|c|c|}
\hline \multirow[t]{2}{*}{ Cognitive } & \multicolumn{10}{|c|}{ Ventricular Measure } \\
\hline & Left & Right & Left & Right & Left & Right & Area & Width & $\begin{array}{c}\text { Bicaudate } \\
\text { Span }\end{array}$ & Total Sig \\
\hline PIQ & -.16 & -.07 & .04 & .04 & $-.18^{\mathrm{a}}$ & -.15 & -.11 & -.13 & -.08 & 1 \\
\hline BVRT & .11 & -.01 & -.03 & -.04 & .09 & .08 & .06 & $.18^{\mathrm{a}}$ & .04 & 1 \\
\hline WF & $-.22^{a}$ & $-.21^{\mathrm{a}}$ & -.08 & -.08 & -.15 & -.14 & -.08 & .14 & -.08 & 2 \\
\hline Mem & $-.23^{\mathrm{a}}$ & $-.18^{\mathrm{a}}$ & -.11 & -.09 & $-.25^{b}$ & -.16 & $-.25^{\mathrm{b}}$ & -.13 & -.09 & 4 \\
\hline Trails A & $.18^{\mathrm{a}}$ & $.18^{\mathrm{a}}$ & .03 & .07 & $.20^{\mathrm{a}}$ & $.23^{\mathrm{a}}$ & .09 & $.26^{\mathrm{b}}$ & $.22^{\mathrm{a}}$ & 6 \\
\hline B & $.21^{\mathrm{i}}$ & $.19^{a}$ & .06 & .09 & $.23^{\mathrm{a}}$ & $.22^{\mathrm{a}}$ & .05 & $.26^{\mathrm{b}}$ & $.26^{\mathrm{b}}$ & 6 \\
\hline PA & -.14 & -.04 & .09 & .09 & -.13 & -.07 & -.11 & .01 & -.04 & 0 \\
\hline Mem Ob. & $-.22^{\mathrm{a}}$ & .17 & $-.21^{\mathrm{a}}$ & .06 & $.27^{b}$ & .13 & $-.22^{\mathrm{a}}$ & $.19^{a}$ & .11 & 5 \\
\hline Total & 5 & 4 & 1 & 0 & 6 & 2 & 3 & 6 & 2 & 29 \\
\hline
\end{tabular}

a: $p \leq 0.05$

b: $\mathrm{p} \leq 0.01$

c: $\mathrm{p} \leq 0.001$

Legend: FIQ, PIQ: Full Scale and Performance Intelligence Quotients respectively; BVRT: Benton Visual Retention Test; WF: Word Fluency; TPTd, nd, both: Tactual Performance Test for dominant, non-dominant and both hands; Mem: memory; PA: paired associated learning; Mem Ob.: memory for objects.

impairment, increased depression and ventricular enlargement. More importantly, the degree of cognitive impairment is related to ventricular enlargement but independent of the level of depression. Therefore, the presence of cognitive impairment cannot be ascribed to depression but to pathological changes within the brain. Although the magnitude of the reported significant correlation is small, there are a number of reasons why these correlations may underestimate the strength of the relationship. The first reason is the fact that this study was designed to evaluate the effects of MS in the mild stages of the disease. Therefore, the degree of ventricular enlargement and cognitive impairment will be limited. Statistically, such limitations in variability may attenuate the magnitude of correlation coefficients. Second, ventricular enlargement, at best, is a secondary measure of disease process in the brain. Specifically, disease activity per $s e$ is found in the white matter and in a variety of sites throughout the brain. Therefore, this activity may or may not affect ventricular size. A related consideration is in classic neurology, cognitive functions to some degree are localized in specific gray matter regions. To date, there is no comparable theory for the effects of white lesions on cognition. For these reasons, one should not expect a strong fit between the cognitive measures and the measures of ventricular enlargement.

A second issue is whether the reported correlations only reflect the physical aspects of MS as some of the test requires motor functions. This hypothesis seems unlikely for two reasons. First, the EDSS, a measure of general disability, was only significantly correlated with one of nine ventricular measures. Second, the test with the highest demands in terms of tactile and motor functions, the TPT, had only four significant correlations of twenty-seven possible. In contrast, for the memory component of this test, a non-motor task, four of nine possible correlations were significant.

In conclusion, the results of this study further buttress the argument that changes in cognitive functions do occur in the mild stages of $\mathrm{MS}^{1-5}$ and these changes are directly related to the disease process ${ }^{1-9}$ and are not the result of secondary phenomena such as depression. The importance of documenting such cogni- tive changes in the individual patient should not be underestimated as these changes may impact more dramatically on the individual's occupational and social domains than the motor/ sensory effects of MS.

\section{APPENDIX}

\section{Description of Neurological Tests}

Benton Visual Retention Test (BVRT): The subject is presented a card with geometric designs for 10 seconds. The card is removed and the subject is asked to reproduce the designs as accurately as possible. Scoring consists of errors in reproduction.

Word Fluency (WF): The subject is told a letter of the alphabet (e.g., F) and asked to give words beginning with that letter. Three letters are used (FAS) and the subject has one minute to respond to each letter. Scoring is the total number of words produced.

Halstead Category (CAT): A series of slide sets are presented to each subject. Each set has a number concept underlying it. The subject is asked to determine what the concept is based on selecting a number (range 1-4). Feedback is given in terms of correct/incorrect responses. Scoring is the total number of errors.

Tactual Performance Test (TPTd, nd, both, mem, loc): The subject is blind-folded and asked to place six different shaped blocks in a form board, first using only the dominant hand, then the non-dominant hand, and finally both hands. Subsequently, the subject is asked to reproduce the shape of the blocks and their position on the board (mem and loc).

Speech Perception (Speech): The subject hears a nonsense syllable and is asked to select from four options the syllable that they heard.

Trails A and B: In Trails A, the subject joins numbered dots. In Trails B, the sequence alphanumeric (e.g., 1 - A - 2 - B) score is the time taken to do the task.

Paired Associate Learning (PA): The subject is presented with twenty word pairs (e.g., cabbage-pen) and then the first word is presented (e.g., cabbage) and the subject responds with 
the second word of the pair (e.g., pen). The task is repeated three times. Scoring is the number of correct pairings.

Memory for Objects (Mem Ob): The subject is presented with 15 common objects for one minute. The subject is then asked to name the objects. Scoring is the number of correct responses.

\section{ACKNOWLEDGEMENTS}

This study was supported by Health and Welfare Canada, while Mr. James was supported by a summer research studentship from the Medical Research Council of Canada.

\section{REFERENCES}

1. Franklin GM, Nelson LM, Filley CM, et al. Cognitive loss in multiple sclerosis: case reports and review of the literature. Arch Neurol 1989; 46: 162-167.

2. Grant I, McDonald WI, Trimble MR, et al. Deficient learning and memory in early and middle phases of multiple sclerosis. J Neurol Neurosurg Psychiatry 1984; 47: 250-255.

3. Jennekens-Schinkel A, van der Velde EA, Sanders EACM, et al. Visuospatial problem solving, conceptual reasoning and sorting behaviour in multiple sclerosis out-patients. J Neurol Sci 1989; 90: 187-201.

4. van den Burg W, van Zomeren AH, Minderhoud JM, et al. Cognitive impairment in patients with multiple sclerosis and mild physical disability. Arch Neurol 1987; 44: 494-501.

5. Young AC, Saunders J, Ponsford JR. Mental change as an early feature of multiple sclerosis. J Neurol Neurosurg Psychiatry 1976; 39: 1008-1013.

6. Rao S. Multiple sclerosis and cognitive dysfunctions. Multiple Sclerosis Q Rep 1985; 6-8.

7. Heaton RK, Nelson LM, Thompson DS, et al. Neuropsychological findings in relapsing-remitting and chronic-progressive multiple sclerosis. J Consult Clin Psychol 1985; 53: 103-110.

8. Rao SM. Neuropsychology of multiple sclerosis: a critical review. J Clin Exp Neuropsychol 1986; 8: 503-542.
9. Rao SM, Hammeke TA, McQuillen MP, et al. Memory disturbance in chronic progressive multiple sclerosis. Arch Neurol 1984; 41 : 625-631.

10. Goodstein R, Ferrell R. Multiple sclerosis-presenting as depressive illness. Arch Neurol 1977; 38: 127-131.

11. Minden S, Schiffer R. Affective disorders in multiple sclerosis review and recommendations for clinical research. Arch Neurol 1990; 47: 98-104.

12. Whitlock F, Siskind M. Depression as a major symptom of multiple sclerosis. J Neurol Neurosurg Psychiatry 1980; 43: 86I-865.

13. Weingartner $\mathrm{H}$, Silberman E. Models of cognitive impairment: cognitive changes in depression. Psychopharmacology 1982; 18: $27-42$.

14. Franklin GM, Heaton RK, Nelson LM, et al. Correlation of neuropsychological and MRI findings in chronic/progressive multiple sclerosis. Neurology 1988; 38: 1826-1829.

15. Reischies FM, Baum K, Brau $\mathrm{H}$, et al. Cerebral magnetic resonance imaging findings in multiple sclerosis: relation to disturbance of affect, drive, and cognition. Arch Neurol 1988; 45: 1114-1116.

16. Brant-Zawadzki M, Fein G, Van Dyke C, et al. MR imaging of the aging brain: patchy white-matter lesions and dementia. Am J Neuroradiol 1985; 6: 675-682.

17. George AE, de Leon MJ, Kalnin A, et al. Leukoencephalopathy in normal and pathologic aging: 2. MRI of brain lucencies. Am J Neuroradiol 1986; 7: 567-570.

18. Gerard G, Weisberg LA. MRI periventricular lesions in adults. Neurology 1986; 36: 998-1001.

19. Masdeu JC, Wolfson L, Lantos G, et al. Brain white-matter changes in the elderly prone to falling. Arch Neurol 1989; 46: 1292-1296.

20. Lezak M. Neuropsychological Assessment, New York: Oxford University Press, 1977.

21. Botwinick J. Neuropsychology of aging. In: Boll T, Filskow S, eds. Handbook of Clinical Neuropsychology. New York: John Wiley and Sons, 1981.

22. Poser CM, Paty DW, Scheinberg L, et al. New diagnostic criteria for multiple sclerosis: guidelines for research protocols. Ann Neurol 1983; 13: 227-231.

23. Kurtzke J. Rating neurologic impairment in multiple sclerosis: an expanded disability status scale (EDSS). Neurology 1983; 33: 1444-1452.

24. Ramm P. Microcomputer Imaging Device (MCID) Imaging Research Inc., St. Catherines, Ontario, 1988. 